\title{
Internacionalización e Interculturalidad desde la perspectiva de la Red de Universidades Indígenas Interculturales y Comunita- rias de ABYA YALA, RUIICAY
}

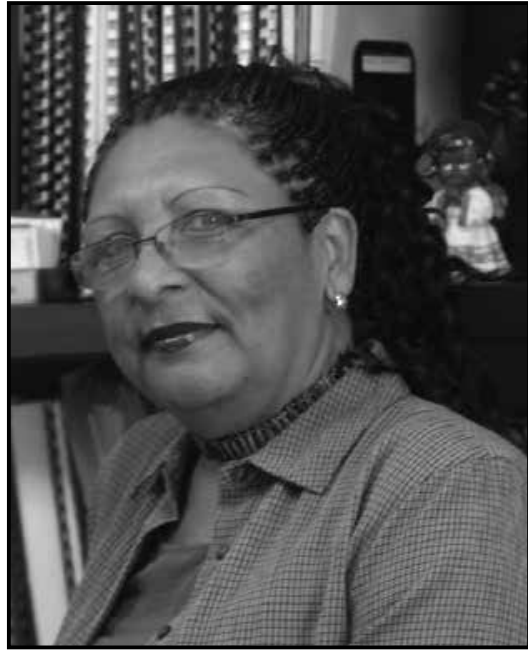

Alta Hooker Blandford'

\section{Resumen}

Tna invitación a reflexionar sobre las matrices culturales que inciden con preeminencia en la Red de

Universidades Indígenas, Interculturales de Abya Yala (RUIICAY), en una praxis donde se conjuga la internacionalización con la interculturalidad, experiencias educativas en la reafirmación de los derechos individuales y colectivos de los pueblos indígenas y afrodescendientes.

\section{Desarrollo}

$\mathrm{Al}$ presentar este documento pretendo compartir con ustedes algunos aspectos que considero relevantes para abordar la Internacionalización e Interculturalidad desde la visión de la red de Universidades Indígenas, Interculturales y Comunitarias de Abya Yala. Abordaré temas como el origen de la RUIICAY, qué nos une, la visión de educación de sus miembros y las acciones emprendidas que conjugan la internacionalización con la interculturalidad, mejores prácticas y principales desafíos.

No sin antes detenernos a examinar y problematizar la manera de cómo la universidad debe responder pertinentemente a las necesidades, sueños, demandas, aspiraciones y proyectos de los diferentes pueblos, considerando al ser humano como una - hebra importante del tejido vivo- y sujeto de derechos individuales y colectivos.

Es importante resaltar que en el nuevo tipo de sociedad: la llamada sociedad del conocimiento y la información y ante todo la sociedad creativa como clave para entender gran parte de las características de la época actual, la internacionalización es interpretada por la educación superior como una de las maneras de afrontar las posibilidades y desafíos de la globalización. Es a la vez un objetivo y un proceso, que permite que las instituciones de educación superior logremos una mayor presencia y visibilidad internacional que genera beneficios².

\footnotetext{
1 Rectora de la URACCAN 4. E-mail: rectoria@uraccan.edu.ni

Este discurso fue pronunciado en: La ciudad de San Miguel de Allende, Guanajuato, México 23 y 24 de Septiembre, 2015.

7mo. Encuentro de Redes Universitarias y Consejos de Rectores y Rectoras de América Latina y el Caribe.

2 ANUIES (1999).
} 
Lo que es también una invitación a reflexionar sobre el verdadero sentido de las universidades en estos momentos. Mejorar la calidad y pertinencia de la docencia, hacer una mejor gestión no tiene sentido en sí misma, sino se convierte en un desafío permanente. Por ello, debemos prestar atención a la calidad de la experiencia educativa que se impulsa en las aulas de clase de cada casa de estudios, tratando siempre de asegurar que se den las posibilidades de interacción entre las matrices culturales diferentes que lleven a generar nuevos conocimientos, saberes y prácticas al servicio de los pueblos.

Sin embargo, los modelos convencionales de universidad forman a profesionales y técnicos desarraigados de su matriz cultural influyendo en la administración del conocimiento para facilitar los procesos de industrialización en menoscabo del medio ambiente y la biodiversidad necesaria para el buen vivir de los pueblos.

A diferencia de la actitud anterior, la propuesta intercultural reconoce las diferencias, y busca utilizarlas para potenciar encuentros fructíferos, para generar niveles de unidad mayores, en los que el diálogo se dé sobre la base del reconocimiento del otro a existir y a desarrollarse.

No se pone aquí el énfasis en los obstáculos que deben servir para fortalecer internamente cada cultura, sino en los puentes que deben multiplicarse y ensancharse. Lo que reconoce una nueva atención a la diversidad cultural es la necesidad de promover más relaciones positivas entre los pueblos. Y enfatizan en formar ciudadanos conscientes de las diferencias, con capacidades para confrontar la discriminación, el racismo y toda forma de exclusión.

Desde hace muchos años, los pueblos luchan por tener su propio modelo educativo, que haga visible su realidad, y que responda a las necesidades y sus expectativas. Una educación que haga evidente su historia, su cultura, sus lenguas, su manera de ver el mundo, los sistemas integrados de conocimientos holísticos, de saberes, enraizado en la fuerza viva de la espiritualidad permite el enriquecimiento de valores éticos, humanistas, refleja la riqueza espiritual, como fuente inagotable de sabiduría y equilibrio armónico del ser humano en su entorno.

Podríamos decir que el contexto que vive América Latina, ha colocado como elemento cen- tral en los lineamientos de los organismos y de los países la elaboración de políticas públicas, a favor de la educación intercultural. No podemos negar el avance y la promoción de diversos instrumentos jurídicos internacionales, nacionales y regionales, constituciones y normativas a favor de la revalorización y respeto por la cultura de los pueblos originarios y afrodescendientes. Las demandas de reconocimiento y de educación planteadas por los pueblos indígenas, afrodescendientes y comunidades étnicas, han tenido eco en los diversos instrumentos jurídicos internacionales, nacionales y regionales.

La Declaración de las Naciones Unidas sobre los derechos de los pueblos indígenas expresa, que la Asamblea General, preocupada por el hecho de que los pueblos indígenas han sufrido injusticias históricas, la colonización y haber sido desposeídos de sus tierras, territorios y recursos, ha impedido ejercer, en particular, su derecho al desarrollo de conformidad con sus propias necesidades e intereses, establece que:

Los pueblos indígenas tienen derecho a todos los niveles y formas de educación del Estado. Todos los pueblos indígenas. También a establecer y controlar sus sistemas e instituciones docentes impartiendo educación en sus propios idiomas y en consonancia con sus métodos culturales de enseñanza y aprendizaje (Art. 14).

También manifiesta que "los pueblos indígenas tienen derecho al reconocimiento a su dignidad y a la diversidad de sus culturas, historias, tradiciones $y$ aspiraciones queden debidamente reflejadas en todas las formas de educación y en la información pública" (Art. 15).

La Conferencia Regional de la Educación Superior en América Latina y el Caribe (CRES, 2008) en la cual participaron más de 3.500 integrantes de la comunidad académica regional (incluyendo directivos, docentes, investigadores, estudiantes, funcionarios, representantes de organismos nacionales, regionales e internacionales y otros interesados en Educación Superior), reconoce la multiculturalidad de nuestros países, por lo que declara:

Nuestra región es marcadamente pluricultural y multilingüe. La integración regional y el abordaje de los desafíos que 
enfrentan nuestros pueblos requieren enfoques propios que valoren nuestra diversidad humana y natural como nuestra principal riqueza.

Además en su Declaración Final incluye algunos valiosos planteamientos sobre el tema. Así, en su acápite $C-3$ sostiene:

Se deben promover la diversidad cultural y la interculturalidad en condiciones equitativas y mutuamente respetuosas. El reto no es sólo incluir a indígenas, afrodescendientes y otras personas culturalmente diferenciadas en las instituciones tal cual existen en la actualidad, sino transformar a éstas para que sean más pertinentes con la diversidad cultural. Es necesario incorporar el diálogo de saberes y el reconocimiento de la diversidad de valores y modos de aprendizaje como elementos centrales de las políticas, planes y programas del sector.

Considerando según la UNESCO (2002), que la diversidad cultural es nuestro patrimonio común y la mayor oportunidad para la humanidad. Es una promesa de renovación y de dinamismo, el motor mismo de la innovación y del desarrollo. Es una invitación al diálogo, al descubrimiento y a la cooperación. En un mundo tan diverso, la destrucción de las culturas es un crimen y la uniformidad un callejón sin salida: todo estriba en valorizar, en un mismo impulso, la diversidad que nos enriquece y los derechos humanos que nos reúnen.

Desde hace muchos años, los pueblos indígenas y afrodescendientes han luchado por tener su propio modelo educativo que se fundamenta desde la ética de la vida, de la reciprocidad, donde el eje vertebrador es la noción de Interculturalidad, como propuesta para aceptar la diversidad y construir un mundo más justo, equitativo y respetuoso. Donde el espíritu de armonía y respeto se irradia con el más cercano. La interculturalidad es concebida como un proceso de relaciones horizontales donde prevalece el diálogo, a través del cual se propicie el conocimiento mutuo, la comprensión, el respeto, el intercambio y la solidaridad entre los pueblos y las culturas.

Abya Yala reclama cambios profundos a la manera tradicional de mirar la ciencia, los conocimientos y la sabiduría. Por lo que nos hemos planteado la misión de transformar la realidad de marginación, exclusión y pobreza en que vivimos y nos hemos propuesto el desarrollo de proyectos estratégicos de universidades indígenas, interculturales y comunitarias en países como México, Guatemala, Nicaragua, Ecuador, Bolivia, Colombia, Venezuela, Argentina, Perú y Chile.

En este sentido, el acceso a una educación intercultural de calidad y pertinente a la cosmovisión, sueños y aspiraciones de los pueblos ha sido y es el reto más importante de las Instituciones de Educación Superior que componen la Red de Universidades Indígenas, Interculturales, Comunitarias de Abya Yala, RUIICAY.

La RUIICAY es una de las redes de la Universidad Indígena Intercultural (UII) del Fondo para el Desarrollo de los pueblos indígenas de América Latina y el Caribe (Fondo Indígena) que en lo referente a su Programa Emblemático de Educación, tiene un Consejo Académico que lo dirige compuesto por las siguientes instancias: Red de Universidades Indígenas, Interculturales y Comunitarias de Abya Yala RUIICAY; Red de Centros Académicos Asociados RECAA; Cátedra Indígena Intercultural CII; Red Continental de Mujeres Indígenas; Red de graduadas y graduados de la UII y las Organizaciones Indígenas CAOI, COICA y CICA.

La Ruiicay está conformada por diez universidades del continente americano: la Pluriversidad Intercultural de las Nacionalidades y Pueblos Indígenas Amawtay Wasi, Casa de la Sabiduría (Ecuador), Universidad Autónoma Indígena Intercultural (UAIIN, Colombia), Universidad Indígena Productiva Aymara Tupak Katari, Universidad Indígena Productiva Quechua "Casimiro Huanca", Universidad Indígena Productiva Guaraní y pueblos de tierras bajas Apiaguaiki Tupak, Universidad Intercultural de los Pueblos del Sur (UNISUR, México), Universidad de Panamá, Universidad Bolivariana de Venezuela, Instituto de Educación Superior Intercultural Campinta Guazu "Gloria Pérez" de Argentina y la Universidad de las Regiones Autónomas de la Costa Caribe Nicaragüense (URACCAN), quien en estos momentos la coordina.

Para nosotras y nosotros la red constituye un espacio donde construimos puentes de confianza, practicamos valores como el respeto, la solidaridad, complementariedad, fundamentado en el diálogo, 
el consenso y la concertación. Uno de nuestros propósitos es tejer la interculturalidad, así mismo trabajar por la interculturalización de la Educación Superior, desarrollando un enfoque intercultural como un tema estratégico, teniendo el pasado y la memoria como elementos de sustentación.

Considerando nuestro trabajo como un aporte al conocimiento universal, visibilizando las diversas cosmovisiones que permiten a los pueblos y nacionalidades originarias mirar de manera diferente la vida, el trabajo, la educación, la familia y la espiritualidad.

La responsabilidad ha sido y es investigar, revalorizar, potenciar los saberes ancestrales, reafirmar lo identitario, defender la madre tierra y construir las ciencias del conocimiento. En efecto, no se trata de reproducir una educación superior que replique el sistema de conocimiento vigente donde los conocimientos indígenas, en el mejor de los casos, son un aspecto circunstancial en el currículo académico. Tampoco se pretende crear un espacio de saber, reservado solamente para los indígenas y afrodescendientes, sino construir contenidos fundamentales que permitan vivenciar la interculturalidad, potenciando la riqueza de los saberes ancestrales, emprender un diálogo teórico practico desde lo intercultural, lo que requiere la construcción de nuevos marcos conceptuales, analíticos, teóricos, en los cuales se vayan generando nuevos conceptos, categorías y nociones, en el marco de la interculturalidad, la calidad y la pertinencia.

Nuestro hermano Luis Fernando Sarango, Rector de la Pluriversidad Amawtay Wasi, comparte lo que le decían sus mayores, que la calidad equivale a hacer las cosas bien. Si tomamos la definición de la UNESCO (1998) sobre calidad, esta sintetiza el espíritu de otras definiciones, donde expresa que la calidad es la adecuación del ser y quehacer de la Educación Superior a su deber ser.

En el desarrollo y fortalecimiento de la RUIICAY hemos asumidos compromisos como:

a. Crear un sistema de Educación Superior Intercultural Continental con Identidad, dentro de un marco de integralidad del conocimiento que permita superar la ruptura entre la práctica y la teoría del conocimiento.

b. Determinar un posicionamiento político y legislativo en torno a la construcción de una nueva sociedad y ciudadanía intercultural convivencial.

c. Impulsar y fortalecer las instituciones de Educación Superior Indígena, Intercultural y comunitaria en el marco de los Estados Nacionales.

d. Promover un sistema de evaluación y acreditación de los centros del conocimiento mayor indígena, intercultural y Comunitaria y de sus modelos educativos.

e. Sistematización y publicación de los procesos de recreación y generación de conocimientos que aporten propuestas y proyectos de vida de los pueblos para el Buen Vivir, Vivir Bien y vivir con Dignidad, fundamentados en procesos investigativos y de emprendimiento con los componentes dialógicos, conceptuales con rigurosidad y profundidad.

f. Generar estrategias para la sostenibilidad económica y financiera de la Red de Universidades.

Para cumplir con estos deberes es importante contar con el ejercicio efectivo de la internacionalización como un espacio de solidaridad internacional que aglutina el conjunto de políticas, proyectos, programas y actividades elaborados para colaborar con personas, pueblos, regiones o el país para mejorar sus condiciones de vida y desarrollar plenamente sus potencialidades hasta alcanzar una vida digna y autónoma, conforme sus cosmovisiones y capacidades propias. Está considerada como una función complementaria de la docencia, investigación y extensión y, a la vez, como un eje transversal de estas actividades.

La internacionalización ha significado la concertación de Planes de Vida Institucionales, preparación de talentos humanos a través de la realización y desarrollo de programas académicos conjuntos, búsqueda de recursos para el fortalecimiento institucional, movilidad de estudiantes y profesores, participación en proyectos, investigaciones, construcción de indicadores de calidad e incidencia para su implementación y acompañamiento técnico académico; se han firmado convenios que han sido parte de los esfuerzos de la RUIICAY, en la ruta de Buen Vivir, el Vivir Bien y el Vivir con dignidad de los pueblos. 
Por tanto, la internacionalización en la red y en URACCAN se puede entender como:

- Un proceso de vinculación estratégica con actores internacionales de desarrollo relevantes para el fortalecimiento de su modelo indígena, intercultural, comunitario y el aporte de este al desarrollo con identidad y la ciudadanía intercultural entre los pueblos y comunidades indígenas, afrodescendientes y mestizas de las regiones autónomas de la Costa Caribe de Nicaragua. Estos actores internacionales son tanto del Norte como del Sur.

- Fortalecimiento del modelo de universidad de URACCAN desde la internacionalización se entiende como un proceso horizontal de enriquecimiento de doble vía. Su práctica se promueve desde la solidaridad, el respeto mutuo y el diálogo intercultural. La internacionalización está estrechamente ligada a la gestión de cooperación internacional o externa, que tiene sus características propias conforme el perfil particular de la Universidad.

En este caminar podemos resaltar tantas experiencias exitosas, concebidas desde un proceso de participación activa, diálogo intercultural, de concertación, de articulación, vinculación de saberes y cosmovisiones diferentes en la búsqueda de un horizonte común, el buen vivir, donde la diferencia y el reconocimiento de la diversidad toman un sentido complementario y de enriquecimiento entre las culturas.

\section{Entre las cuales se pueden mencionar:}

- La formación de talentos humanos en programas de maestrías conjuntas como: Comunicación Intercultural, Cosmovisiones del Buen Vivir/Vivir Bien con énfasis en cambio climático, complementariedad $\mathrm{y}$ equidad.

- El uso efectivo de las tecnologías de información y comunicación (TIC): como efecto trasversal que está contribuyendo a la internacionalización de la educación, permitiendo acortar las distancias, expandir la educación más allá de las fronteras y la educación en red y viabilizar nuevas prácticas pedagógicas.
- Avances del Sistema de Evaluación y Acreditación de Universidades Indígenas, Interculturales y Comunitarias como una manera de asegurar la calidad desde nuestro modelo educativo, con nuestros propios referentes pertinentes para mirarnos, revisarnos y reflexionar.

- Espacios de concertación y vivencias desde y para la interculturalidad.

- Elaboración de propuestas sobre modelos de formación, investigación y acompañamiento a los pueblos, con la participación y respaldo de los mismos.

- Construcción de sistema de conocimientos con visiones ancestrales.

- Construcción de espacios que permiten la circulación de los conocimientos y sabidurías de los pueblos, así como el diálogo de saberes.

Si bien pueden observarse algunos avances significativos, todavía tenemos muchos retos y acciones por realizar para lograr la verdadera «internacionalización» de la Educación Superior. Entre los desafíos que cada vez se hacen más urgentes tenemos:

Construir nuestros propios procesos de aseguramiento de la calidad, donde contemos con referentes pertinentes que nos permitan pensarnos, mirarnos, revisarnos, reflexionar y en algunos casos existir.

En las perspectivas de futuro, tenemos previsto fortalecer la internacionalización en el espacio auto gestionado de la RUIICAY, como un espacio de unión en la diversidad que garantice servir de enlace para el encuentro del pensamiento de las diversidades y abrazar más gente en el marco de enriquecer las experiencias. 